\title{
O ENSINO DE LIBRAS EM AMBIENTES VIRTUAIS DE APRENDIZAGEM: UMA EXPERIÊNCIA PIONEIRA NA UNIDADE VIRTUAL DE CURSOS A DISTÂNCIA DA SECRETARIA DE EDUCAÇÃO DO RECIFE - UNIREC
}

\author{
RECIFE/PE MAIO/2018
}

\author{
Terezinha Monica Sinício Beltrão－SE - Recife - terezinhamonica.ead@gmail.com \\ Tipo: Relato de Experiência Inovadora (EI) \\ Categoria: Estratégias e Políticas \\ Setor Educacional: EDUCAÇÃO CONTINUADA EM GERAL
}

\begin{abstract}
RESUMO
Este trabalho apresenta uma experiência pioneira da UniRec na oferta de curso da Língua Brasileira de Sinais - Libras, na modalidade a Distância, utilizando a Plataforma Moodle. A Língua Brasileira de Sinais - Libras, é também, como a Língua Portuguesa, língua oficial do Brasil, no entanto é dominada por poucos. Os estudantes surdos da Rede Municipal de Ensino do Recife, necessitam de interlocutores em sua língua materna também no espaço escolar, na medida em que precisam se comunicar com todos os que fazem a escola, por isso foram elaboradas estratégias para o aprendizado da Libras em um curso a distância para professores da educação básica. O Curso de Libras Básico 1 foi ofertado para 100 (cem) professores da rede pública municipal de ensino do Recife. As estratégias de ensino e de aprendizagem especificamente voltadas para o ensino da Libras a distância que foram efetivadas por meio da UniRec foram discutidas com experientes professores surdos de Libras. Assim, foi organizado o curso de Libras Básico 1 em 10 (dez) semanas no período de 31 de outubro de 2017 a 29 de janeiro de 2018. Em cada semana foi disponibilizado para os professores/cursistas: videoaulas apenas com Libras e as mesmas videoaulas com Libras e legendas em Português, bem como textos e atividades com os conteúdos do Curso. Todos os professores conteudistas, formadores e Tutores que atuaram no referido curso são surdos.
\end{abstract}

Palavras-chave: Libras - Educação a Distância - Comunicação - Inclusão - Surdos

\section{AGRADECIMENTOS}

AOS ESTUDANTES SURDOS DA EDUCAÇÃO BÁSICA DA REDE PÚBLICA DE ENSINO DO RECIFE QUE NOS ESTIMULA A PENSAR EM MANEIRAS INOVADORAS DE ASSEGURAR A APRENDIZAGEM PLENA COM INCLUSÃO DE FATO. 


\section{Introdução}

Este trabalho apresenta uma análise da experiência da oferta de curso básico de Libras para professores da educação básica da rede pública do Recife. Curso que foi oferecido na modalidade de Educação a Distância - EaD, pela Unidade Virtual de cursos a Distância - UniRec, utilizando a plataforma Moodle. Organizado em parceria com a Gerência de Educação Inclusiva da Secretaria de Educação do Recife e teve como finalidade instrumentalizar professores da rede pública de ensino do Recife para uma comunicação básica com os seus alunos surdos e assim, favorecer a participação destes nas atividades do dia a dia da escola, contribuindo para a inclusão escolar dos estudantes surdos.

A proposta teve sua gênese na necessidade de promover a apropriação da Libras por todos os segmentos da escola, uma vez que, há estudantes surdos e que estes precisam de interlocutores que possam se comunicar na sua língua materna.

O referido curso que foi organizado em dez semanas, nas quais eram disponibilizadas videoaulas com Libras e legendas em Português e videoaulas apenas com Libras, como também textos e atividades com os conteúdos do Curso.

Também foi utilizado o livro texto, Libras em Contexto, para consulta em algumas das semanas e como material complementar também foi utilizado o Dicionário Digital de Libras.

Por meio da troca de mensagens entre os tutores e os cursistas, foi possível dirimir dúvidas e dar feedback aos professores/cursistas para melhor apropriação do conteúdo do curso, favorecendo a construção do conhecimento.

\section{Objetivo Geral}

Contribuir com a disseminação da Língua Brasileira de Sinais a fim de promover a inclusão dos estudantes surdos nas escolas municipais do Recife e a comunicação entre surdos e ouvintes.

\section{Objetivos Específicos}

- Promover a disseminação da Língua Brasileira de Sinais - Libras.

- Favorecer a inclusão dos estudantes surdos nas escolas públicas municipais.

- Incentivar a interação entre surdos e ouvintes. 


\section{Referencial Teórico}

A Língua Brasileira de Sinais - Libras, por meio da Lei oㅜ 10.436, de 24 de abril de 2002, foi reconhecida como meio legal de comunicação e expressão, portanto também se constitui como língua oficial do Brasil.

A iniciativa da Secretaria de Educação do Recife para a oferta dos cursos de Libras na plataforma Moodle, pela UniRec, deveu-se à necessidade de disseminar a Língua Brasileira de Sinais - Libras, e atender à demanda das escolas municipais e aos estudantes surdos, na perspectiva da inclusão.

$\mathrm{Na}$ modalidade de educação a distância o ensino permite que professores, tutores e estudantes não necessariamente estejam num mesmo espaço físico e os estudantes podem interagir em diferentes momentos com os tutores. Esse trabalho de tutoria é extremamente importante, pois complementa a formação do estudante através da orientação, realizada por profissional qualificado. (ARREDONDO; GONZÁLEZ; GONZÁLEZ, 2011).

O Art. 20 da Lei no 10.436, de 24 de abril de 2002, diz que " Deve ser garantido, por parte do poder público em geral e empresas concessionárias de serviços públicos, formas institucionalizadas de apoiar o uso e difusão da Língua Brasileira de Sinais Libras como meio de comunicação objetiva e de utilização corrente das comunidades surdas do Brasil".

Nessa direção, foram concentrados esforços no sentido de, por meio da educação a distância, disponibilizar aos professores da educação básica da rede pública de ensino do Recife, um curso básico de Libras permitindo, entre outras coisas, ampliar as possibilidades de interação entre surdos e ouvintes no espaço escolar, fomentar a formação aos professores e favorecer a inclusão dos estudantes surdos, na medida em que essa ação auxilia na disseminação da Libras.

\section{Procedimentos Metodológicos}

O Curso de Libras Básico 1, foi ofertado com o intuito de favorecer a inclusão dos estudantes surdos das escolas públicas da rede municipal de ensino do Recife, por meio da formação dos professores da educação básica (que aqui chamaremos de professores/cursistas) na Língua Brasileira de Sinais - Libras. Foi organizado num formato e modalidade que possibilitasse a participação dos professores/cursistas, visto que poderiam realizar os seus estudos no tempo e espaço que melhor lhes conviesse. 
O formato do curso foi pensado pela UniRec e discutido com professores surdos com vasta experiência no ensino de Libras, assim foi sistematizado o curso que teve apenas um encontro presencial no início das atividades para a apresentação da plataforma, uma vez que os professores conteudistas, formadores e tutores, todos surdos, bem como os professores/cursistas, tinham pouca familiaridade com a plataforma.

Foram contratados 2 (dois) professores conteudistas e formadores para gravação das videoaulas e proposição das atividades e 5 (cinco) tutores para o acompanhamento dos professores/cursistas no AVA e correção das atividades.

As videoaulas foram gravadas e editadas por profissionais da UniRec ficando a cargo da coordenação do curso, que por também ter experiência com educação inclusiva, discutia com as professoras conteudistas e formadoras o formato e a organização das atividades.

O referido curso foi oferecido no período de 31 de outubro de 2017 a 29 de janeiro de 2018 em dez módulos, sendo um por semana. Em cada módulo foi disponibilizado para os professores/cursistas: videoaulas, atividades, textos em PDF e fóruns para dirimir dúvidas e fomentar discussões.

As atividades de cada semana tinham prazo determinado para realização. O Livro texto utilizado no curso, o material complementar e o calendário ficaram disponíveis por todo o período do curso; as videoaulas, uma vez abertas, ficaram disponíveis até o final do curso; tudo isso para que os professores/cursistas pudessem consultar os materiais sempre que necessário. O referido Calendário do Curso apresentava, além das datas, o que seria tratado em cada semana.

Nas videoaulas era tratado o conteúdo da semana e as orientações para a realização das atividades eram feitas ou pela videoaula ou pela própria atividade apresentada no AVA.

Em todas as semanas, com exceção da semana 8(oito), que teve a atividade de postagem de texto, os professores/cursistas construíram, gravaram e postaram vídeos com as respostas das atividades em Libras, possibilitando que os tutores surdos avaliassem a desenvoltura dos professores/cursistas na Libras.

\section{Apresentação e discussão dos resultados}

Procederemos a seguir com a apresentação e discussão dos resultados referentes ao 
Curso de Libras Básico 1. Os dados foram construídos a partir dos relatórios disponibilizados pela Plataforma Moodle, utilizada para a realização do referido curso.

Participação nas atividades:

O gráfico a seguir apresenta o quantitativo de cursistas que respondeu a cada uma das atividades propostas no curso:

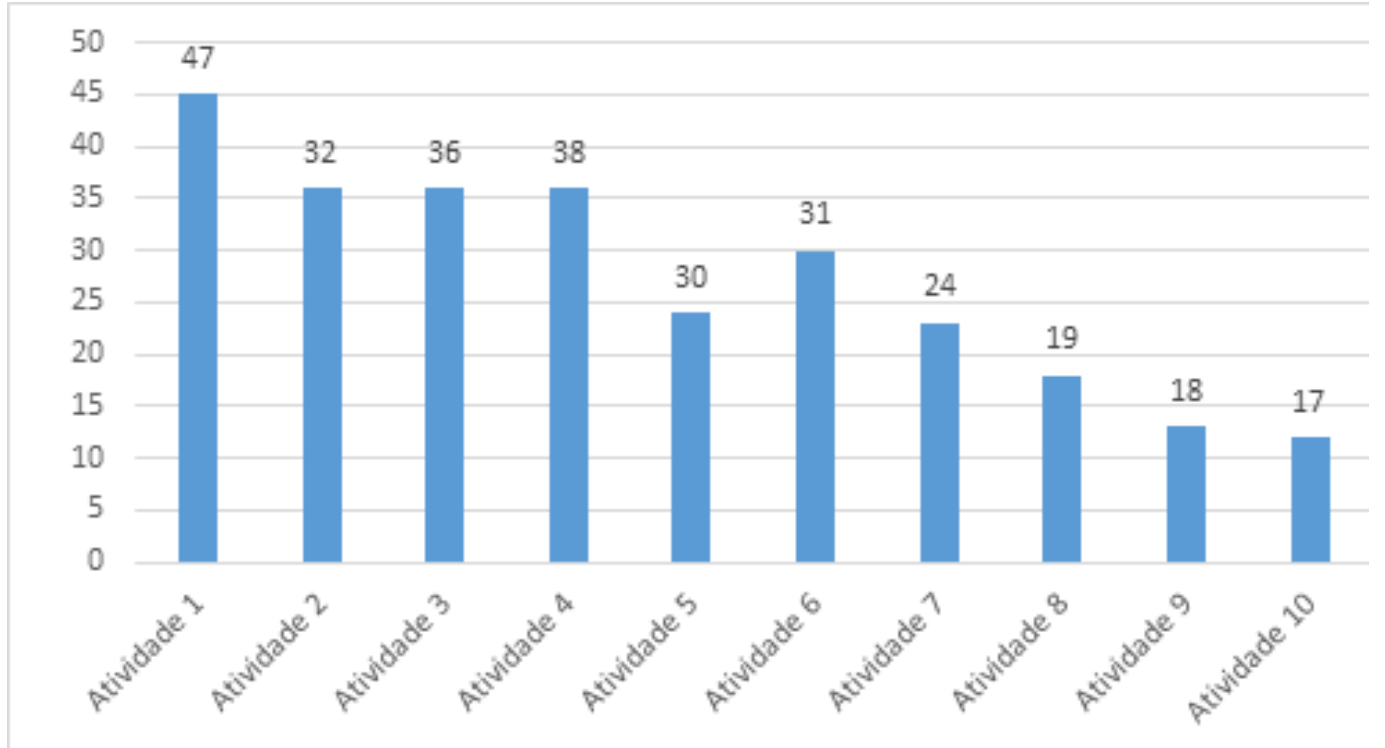

Gráfico 1. Quantidade de envios por atividade

Com exceção de uma atividade que a foi de postagem de texto, todas as demais foram de postagem de vídeos com as respostas em Libras que eram avaliadas pelos tutores surdos. Atendemos pelo AVA alguns dos professores/cursistas que manifestaram dificuldade de realizar a atividade neste modelo de postagem de vídeos, pela pouca familiaridade de produzir os vídeos e proceder com a postagem deste arquivo. Orientamos que os vídeos poderiam ser produzidos utilizando os seus Smartphones e postados o próprio vídeo na atividade ou ainda poderiam ser colocados no YouTube e postado o link.

- Acesso ao Fórum de dúvidas e discussões:

No que se refere aos acessos ao fórum de dúvidas e discussões houve 3.506 participações nos fóruns. Segundo SOARES, E. L., 2015 O fórum é uma ferramenta de interação que fortalece ativamente a rede de construção de conhecimento. Utilizamos esse fórum para dirimir as dúvidas durante todo o curso, como também para fomentar discussões, a exemplo da semana que tratamos sobre a Cultura e a Comunidade Surda. 
Avaliamos que a participação dos professores/cursistas favoreceu boas discussões oportunizando a construção do conhecimento.

- Professores/cursistas concluintes:

As inscrições para a participação no curso foram limitadas em 100 (cem), pois foi acordado que o número de participante seria limitado em 20 (vinte) para cada tutor, para um atendimento mais individualizado, por se priorizar nas atividades solicitadas a postagem de vídeos com as respostas todas em Libras, haveria assim, possibilidade de melhor atender aos professores/cursistas.

O gráfico abaixo apresenta a situação final dos professores/cursistas:

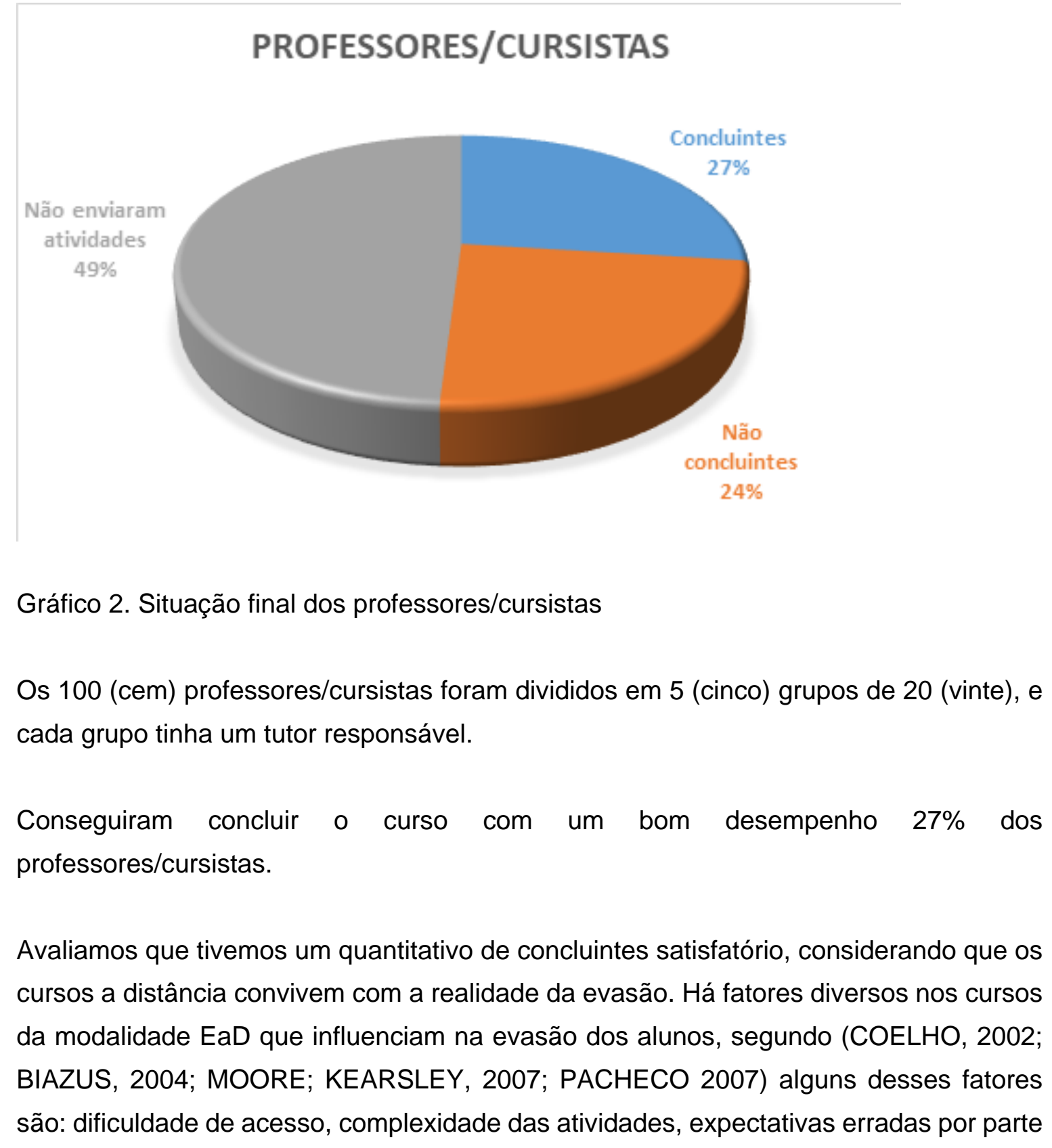


dos alunos, falta de habilidade para usar a tecnologia corretamente e tempo de realizar os estudos.

Dentre os 49 cursistas que não enviaram nenhuma atividade, 29 se inscreveram, mas nunca acessaram a plataforma.

O gráfico a seguir apresenta a média das notas em cada uma das dez atividades aplicadas aos cursistas que concluíram o curso. A cada atividade realizada era atribuída uma nota de 0 a 10.

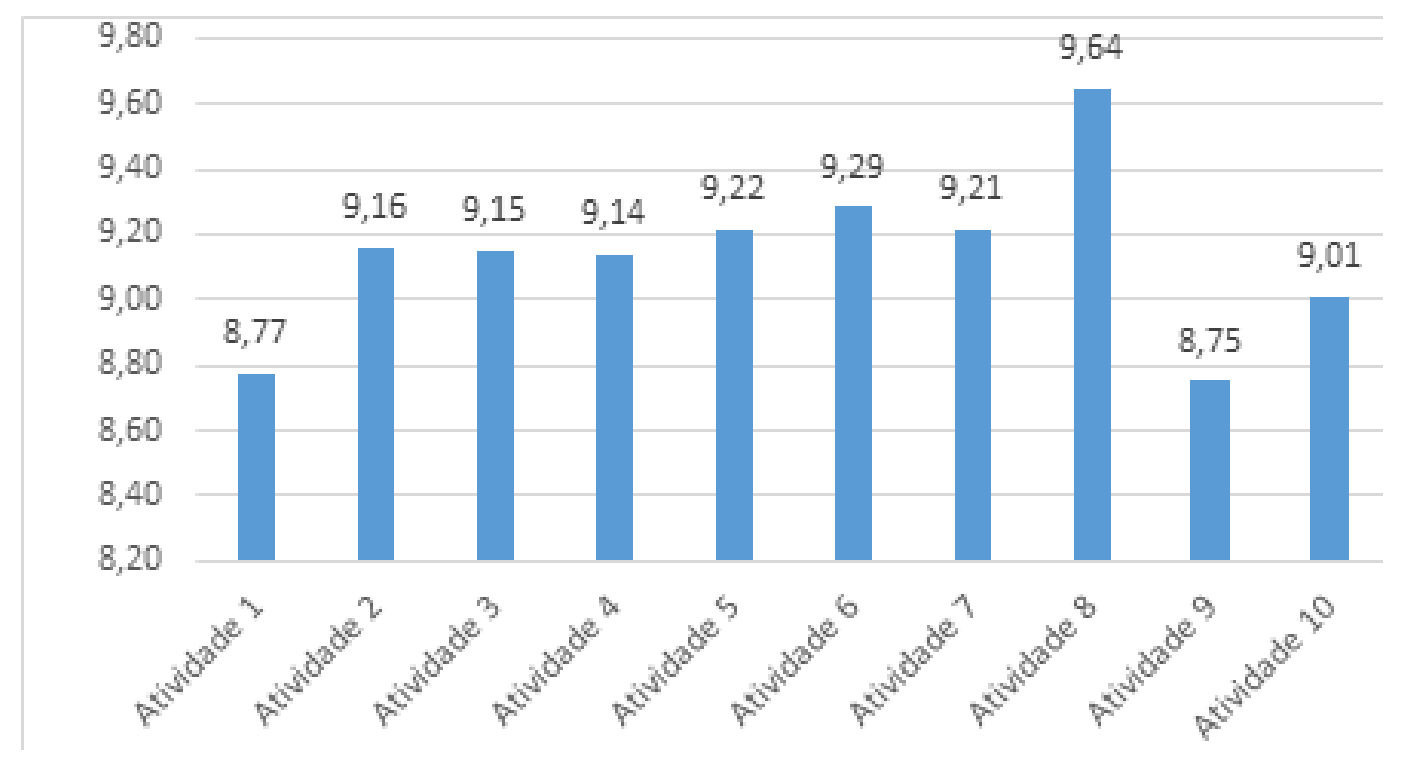

Gráfico 3. Média das notas das atividades do curso Libras Básico 1

Pode-se verificar que a Atividade 8 (oito) teve a maior média em comparação com as demais. Isso pode ter acontecido pelo fato de que a atividade 8 (oito) foi de postagem de texto; resultado que coaduna com o fato dos professores/cursistas apontarem dificuldades na postagem de vídeos.

Foram considerados aprovados os cursistas que tiveram bom desempenho em pelo menos 6 (seis) das 10 (dez) atividades. O gráfico abaixo apresenta o quantitativo de atividades realizadas pelos cursistas que concluíram o curso: 


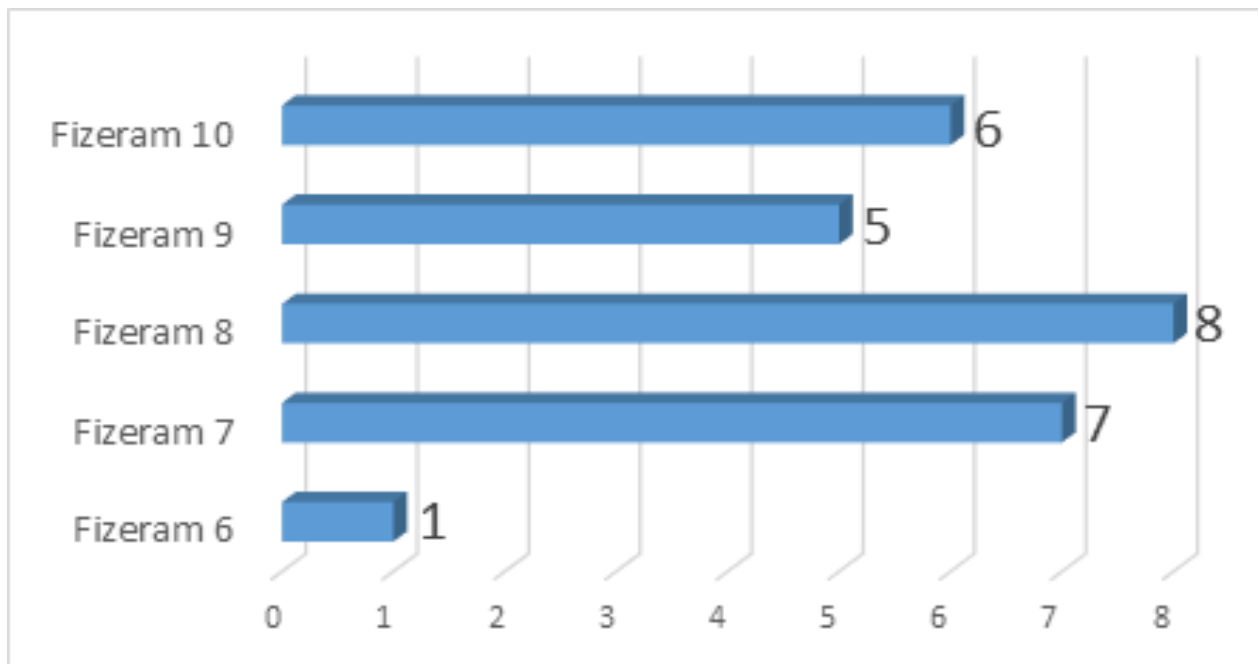

Gráfico 4. Quantidade de atividades realizadas pelos cursistas concluintes

A maior parte dos cursistas que concluíram o curso Libras Básico 1 obtiveram média entre 9 (nove) e 10 (dez). O gráfico a seguir apresenta como ficaram as médias dos cursistas que concluíram o curso:

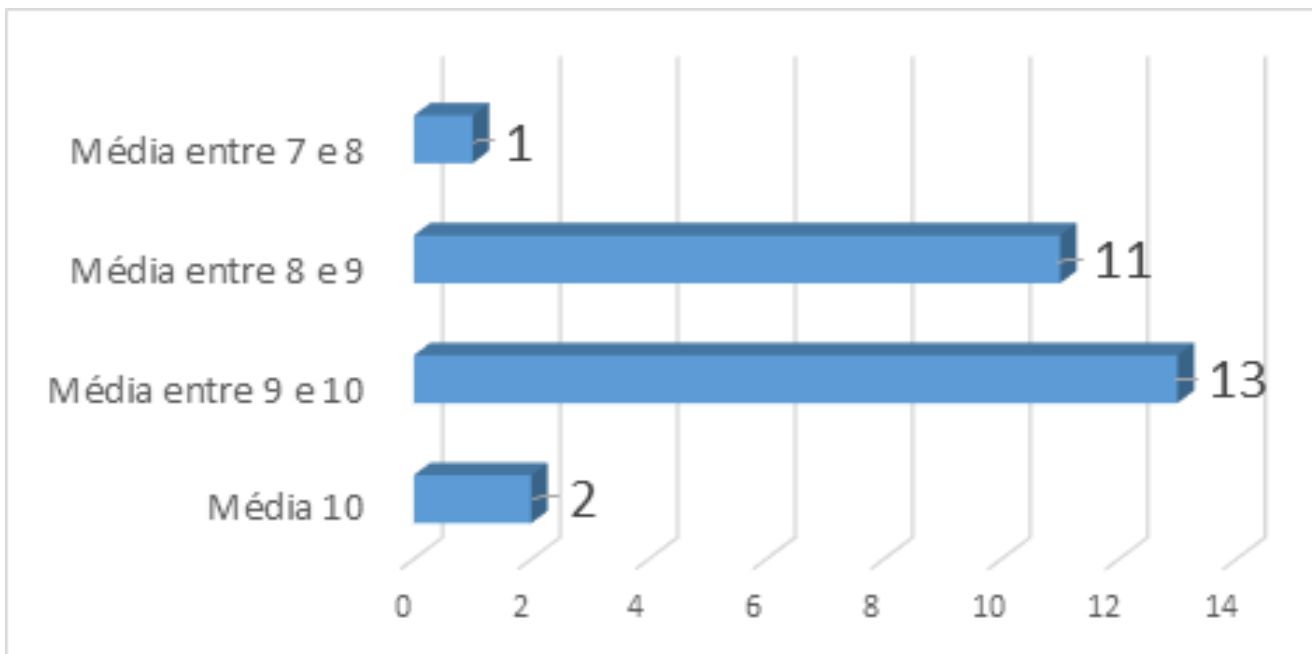

Gráfico 5. Média por quantidade de professores/cursistas concluintes

As médias dos cursistas que concluíram o curso demonstram o empenho dos professores/cursistas, podendo refletir a razão apontada pela pesquisa de Mercado, (2007) que aponta como um aspecto positivo para o sucesso de cursos em EaD apresentar atividades que promovam a aprendizagem ativa mediante tarefas e práticas motivadoras. 
Ainda é um desafio importante atender aos estudantes público alvo da Educação Especial, em classes comuns do ensino regular nas muitas cidades do nosso país.

No Decreto 5.626 de 22/12/2005 no Art. 14 Inciso V, que trata acerca do uso e da difusão da Língua Brasileira de Sinais - Libras e da língua portuguesa para o acesso das pessoas surdas à educação, reza que se deve apoiar na comunidade escolar, o uso e a difusão de Libras entre professores, alunos, funcionários, direção da escola e familiares, inclusive por meio da oferta de cursos. Entendemos ser isso responsabilidade não apenas de instituições Federais de ensino, mas de toda e qualquer instituição de ensino, sobretudo as instituições públicas.

Nesse sentido, algumas ações têm sido implementadas, e, o curso de libras que foi construído e ofertado para os professores educação básica da rede pública de ensino do Recife é uma dessas iniciativas.

O modelo do curso e a utilização da modalidade a Distância para a oferta do Curso de Libras possibilitou que os professores/cursistas pudessem ter contato com a Libras nos horários que lhes fossem mais convenientes, bem como que, por meio do acesso às videoaulas e aos demais materiais pudessem rever tantas vezes quantas fossem necessárias o que precisassem para a construção do conhecimento.

Assim como a educação inclusiva, a educação a distância encontra importantes resistências no nosso país. Juntar essas modalidades num curso de Língua é tanto mágico, do ponto de vista do encanto, quanto árduo, no que se refere às dificuldades que, por vezes, sem razão, são expressas. Por isso é importante que ações como essa, sejam multiplicadas em nosso país.

\section{Referências}

ALMEIDA, O. C. de S. et al. Evasão em cursos a distância: fatores influenciadores. Acesso em: 23 Março 2018.

ARREDONDO, S. C; GONZÁLEZ, A. T; GONZÁLEZ, L. P. Formação de tutores: fundamentos teóricos e práticos. Curitiba: Ibpex, 2011.

BIAZUS, C. A. Sistema de fatores que influenciam o aluno a evadir-se dos cursos de graduação na UFSM e na UFSC: um estudo no curso de Ciências Contábeis. 2004152 f. Tese (Doutorado)-Programa em Engenharia de Produção, Universidade Federal de Santa Catarina, 2004. 
BRASIL. LEI № 10.436, de 24 de abril de 2002. Disponível em: < http://www.planalto.gov.br/ccivil_03/leis/2002/10436.htm> Acesso em: 02 Abril 2018.

BRASIL. Decreto 5.626 de 22 de dezembro de 2005. Disponível em < http://www.planalto.gov.br/ccivil_03/_ato2004-2006/2005/decreto/d5626.htm> Acesso em: 29 Março 2018.

COELHO, M. L. A evasão nos cursos de formação continuada de professores universitários na modalidade de educação a distância via internet. Minas Gerias: UFMG, 2002.

MERCADO, P. L. M. Dificuldades na Educação a Distância Online. < http://www.abed.org.br/congresso2007/tc/55200761718PM.pdf> Acesso em 06 Abril 2018.

MOORE, M. G; KEARSLEY, G. Educação a distância: uma visão integrada. São Paulo: Thomson Learning, 2007.

PACHECO, A. S. Evasão: análise da realidade do curso de graduação em Administração a Distância da Universidade Federal de Santa Catarina. Dissertação (Mestrado) Programa de Pós-Graduação em Administração, Universidade Federal de Santa Catarina, Santa Catarina, 2007.

SOARES, E. L. O. C. de S. et al. Fórum: meio de interação na ead.< http://www.abed.org.br/hotsite/20-ciaed/pt/anais/pdf/205.pdf > Acesso em: 02 Abril 2018. 